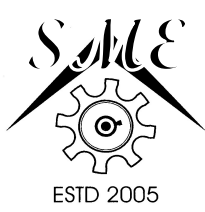

\title{
A STUDY ON DEPOSITION OF ELECTRODE MATERIALS ON MAGNESIUM ALLOY USING ELECTRICAL DISCHARGE COATING TECHNIQUE
}

\author{
"Elaiyarasan $\mathbf{U}^{1}$, Satheeshkumar $\mathrm{V}^{2}$ and Senthilkumar $\mathrm{C}^{3}$
}

${ }^{1}$ Department of Mechanical Engineering, Karpaga Vinayaga College of Engineering and Technology, Madhuranthagam, Tamil Nadu-603308, India ${ }^{2}$ Department of Mechanical Engineering, Government College of Engineering, Salem, Tamil Nadu-636011, India ${ }^{3}$ Department of Mechanical Engineering, University College of Engineering, Panruti, Tamil Nadu-607106, India https://doi.org/10.37255/jme.v15i3pp60-65

\begin{abstract}
In this present research, an attempt has been made to deposit the $\mathrm{WC} / \mathrm{Cu}$ composite coating on the ZE41A magnesium alloy using electrical discharge coating technique. Tungsten carbide and copper powders with a particle size of $4 \mu \mathrm{m}$ were used as the electrode materials. Electrodes are prepared in the combination of WC70: Cu30 under different load (150 MPa, $175 \mathrm{MPa}, 200 \mathrm{MPa})$ using powder metallurgy technique. In this experiment, compaction pressure, current and pulse on time were selected as the input process parameters and response were material deposition rate (MDR), layer thickness (LT) and microhardness (MH). From the results, it was revealed that the MDR, LT and $\mathrm{MH}$ increase with an increase in discharge current and pulse on time and decreases with increases in compaction pressure. Microstructural evaluation on the deposited surface was performed by using scanning electron microscopy (SEM). More prominent craters formed in the deposited region results in the lower surface finish. Energy dispersive spectroscope (EDS) test was carried out to confirm the electrode materials deposited on the workpiece surface.
\end{abstract}

Keywords: Electrical discharge coating, Powder metallurgy, ZE41A magnesium alloy, Material migration rate, Layer thickness and SEM.

\section{Introduction}

Electrical discharge machining (EDM) is one among the electrothermal processes, is used for machining the materials involved high hardness and strength. During EDM, unwanted material is removed by an electrochemical reaction between the electrode and workpiece [1]. Due to high accuracy and precision, EDM is applied in several industries such as automobile, aerospace, aircraft and tool making industries. Even though the formation of recast layer in the machining zone is the common occurrence that affects the surface roughness [2]. By increasing the deposition of the recast layer in the machining region, surface properties can be improved. This novel approach by the EDM is called electrical discharge coating (EDC).

EDC is the material transfer process of EDM, is applied for depositing the wear and corrosion-resistant coating on the workpiece [3]. Nowadays, several EDC experiments conducted to modify the surface of the base materials. The powder metallurgy electrode plays a vital role in EDC application [4]. Liew et al. [5] have conducted EDM experiments to migrate the electrode materials on the silicon carbide surface in order to enhance the material deposition rate and surface roughness. Ahmed [6] investigated the deposition of electrode materials consisting of titanium, boron carbide and aluminium on the aluminium surface using the method. Mussada and Patowari [7] have fabricated the $\mathrm{W}-\mathrm{Cu}$ powder metallurgy green compact electrode for depositing the uniform coating layer on the aluminium alloy surface, and they achieved maximum MTR and minimum surface roughness. The experiment conducted under different controlled parameters such as compaction load, current, pulse on time and pulse of time. Prakash et al. [8] have modified the titanium alloy surface using $\mathrm{Ti}-\mathrm{Nb}$ powder compact sintered electrode. Current and pulse on time were selected as the parameter. Layer thickness, deposition rate, microhardness increases with an increase in current and on time in this investigation. Huang et al. [9] conducted the experiment to modify the titanium alloy (Ti-6Al$4 \mathrm{~V}$ ) surface using $\mathrm{P} / \mathrm{M}$ electrode by EDM. Effect of discharge current, pulse duration and machining time on material removal rate, tool wear rate and overcut have been studied. In the above literature, investigation on migration/deposition of electrode materials on the workpiece materials using powder compact electrode have been studied but effect of sintered electrode in 
EDC is very limited. Mohanty et al. [10] have produced the uniform coating on the Ti6Al4V workpiece using deionized water mixed with tungsten disulphide. Different surface characteristics such as material deposition rate, surface roughness and microhardness were achieved successfully by controlled parameters such as current, discharge voltage and pulse duration Tijo et al. [11] increased the wear resistance of AISI 1020 steel surface coated with $\mathrm{TiC}$ and $\mathrm{Cu}$ composite electrode. Influence of peak current and pulse on time on the material deposition rate and microhardness were studied. Different characterization techniques such as SEM, EDS and XRD have been carried out to assess the coated surface. In above-studied researches, several hard workpiece materials modified using EDC, but few experiments have been tried on the soft materials like aluminium. Lightweight materials are widely used in the diverse of application such as automobile and aerospace due to its superior mechanical properties, but tribological properties of such material are poor, so it is not easy to use in engineering application. In this present investigation, the surface of the magnesium alloy is modified using electro-discharge coating technique with $\mathrm{WC}-\mathrm{Cu}$ powder metallurgy electrode. Effect of compaction load, current and pulse on time on the material deposition rate (MDR), layer thickness (LT) and microhardness $(\mathrm{MH})$ are studied. Further different characterization techniques such as SEM and EDS have been carried out to analysis the deposited magnesium alloy.

\section{Experimental procedure}

\subsection{Materials and Methods}

In this investigation, electrodes were prepared using tungsten carbide and copper powders through powder metallurgy method. The average particle size of the electrode powder was 2-4 microns. First, the selected powders were taken in the combination of WC70: $\mathrm{Cu} 30$ (wt \%) and mixed thoroughly using ball mill for 4 hours. The mixed powders compacted in different load with the help of punch and die setup of $10 \mathrm{~mm}$ diameter using a hydraulic press. The load applied during the compaction was $150 \mathrm{MPa}, 175 \mathrm{MPa}$ and $200 \mathrm{MPa}$. Further, the prepared green compact electrodes were sintered at $900 \mathrm{oC}$ using a tubular furnace in the argon gas atmosphere for $30 \mathrm{~min}$. ZE41A magnesium alloy was selected as the base materials in this research, and its chemical composition is given in Table1. Before the experiment, the workpiece materials were prepared for the dimension of $20 \mathrm{~mm} \times 20 \mathrm{~mm}$. In this experiment, the 5530 EDM E-series machine was used for depositing electrode materials on the magnesium alloy surface. EDM oil was used as a dielectric fluid supplied between the electrode and workpiece for controlling the temperature.

Table 1 Chemical composition of ZE41A Magnesium alloy (wt \%)

\begin{tabular}{cccccccccc}
\hline $\mathbf{S i}$ & $\mathbf{C u}$ & $\mathbf{Z n}$ & $\mathbf{Z r}$ & $\mathbf{F e}$ & $\mathbf{T R E}$ & $\mathbf{N i}$ & $\mathbf{M n}$ & $\mathbf{A l}$ & $\mathbf{M g}$ \\
\hline 0.003 & 0.002 & 3.80 & 0.60 & 0.004 & 1.18 & 0.002 & 0.003 & 0.006 & $\mathrm{Bal}$ \\
\hline
\end{tabular}

Table 2 Process parameters and their levels used in the study

\begin{tabular}{ccccc}
\hline Parameter & Unit & $\begin{array}{c}\text { Low } \\
(-1)\end{array}$ & $\begin{array}{c}\text { Levels } \\
\text { Medium } \\
(0)\end{array}$ & $\begin{array}{c}\text { High } \\
(1)\end{array}$ \\
\hline $\begin{array}{c}\text { Compaction } \\
\text { load (CL) }\end{array}$ & $\mathrm{MPa}$ & 150 & 175 & 200 \\
Current (I) & $\mathrm{A}$ & 2 & 3 & 4 \\
Pulse on time (Ton) & $\mu \mathrm{s}$ & 50 & 70 & 90 \\
\hline
\end{tabular}

EDC experiment conducted with different controlled parameters such as compaction load, current and pulse on time. The parameters and their levels are given in Table 2. Experiment planned using central composite design of response surface methodology (RSM). Twenty experiments conducted in a different condition to study the effect of the individual parameters. Fixed time of each experiment was $10 \mathrm{~min}$. Material deposition rate (MDR), layer thickness (LT) and microhardness $(\mathrm{MH})$ were a response in this study. MDR calculated by weight difference between the before and after EDC of the workpiece. MDR measured using SF400D weighing machine, and microhardness of the deposited workpiece was measured by Vicker's hardness tester (Model: Zwick 3212) available at Annamalai University, Chidambaram. The microstructure of the migrated workpiece was evaluated by scanning electron microscopy (SEM), and electrode material deposited on the workpiece surface was confirmed by the energy dispersive spectroscope (EDS). The cross-sectional area of the deposited workpiece was measured to find the layer thickness. Three different thickness values were taken in each specimen, and the average value was considered as the layer thickness value.

\section{Result and Discussion}

\subsection{Cross-section analysis of the migrated workpiece}

Twenty experiments were carried out for different controlled parameters. Electrode material was deposited on the workpiece in all condition of the experiment as confirmed by EDS. Even though, EDC with high compaction load electrode provided lower deposition rate, which reduces the deposited layer thickness. Fig.1 shows the initial microstructure of the 
Journal of Manufacturing Engineering, September 2020, Vol. 15, Issue. 3, pp 060-065

base materials and deposited workpiece. At high compaction load with lower current and pulse on time produced the insufficient plasma arc that formed the globules and bigger craters in the deposited surface. Due to its bigger sized globules and craters, deposited workpiece became hardened. Hence, the surface had a poor surface finish.
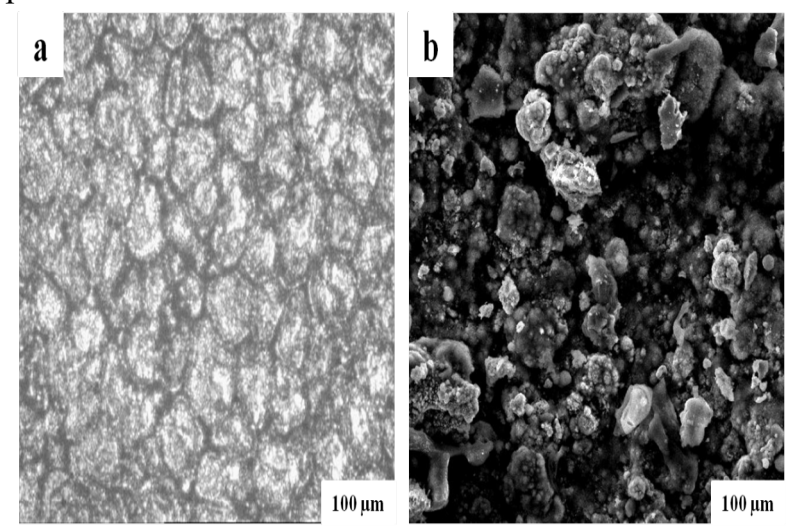

Fig. 1 Microstructure (a) ZE41A Mg alloy and (b) WC/Cu coated ZE41A Mg alloy

Electrode prepared with low compaction load increased the MDR, which increases the thickness of the coating layer as depicted in Fig.2. Quantitative elemental analysis by EDS revealed deposition of electrode materials on the workpiece surface, as shown in Fig.3. Fig.3a and Fig. 3b shows the EDS analysis of deposited surface at $150 \mathrm{MPa}$ and $200 \mathrm{MPa}$, respectively. The peaks of copper $(\mathrm{Cu})$, Magnesium $(\mathrm{Mg})$, Iron $(\mathrm{Fe})$, Nickel $(\mathrm{Ni})$, Tungsten $(\mathrm{W})$, Oxygen $(\mathrm{O})$ and Carbon (C) confirmed the electrode materials deposited in the workpiece surface. SEM image of the different condition of experiments is shown in Fig. 4. Fig. 4a-b indicated small cracks and pores that affect the roughness of the deposited workpiece. Fig. $4 \mathrm{c}$ shows the bulk deposition of electrode materials that developed the bigger craters. Fig. 4d-f shows the SEM microstructure of the globules. Fig. $4 \mathrm{~g}-\mathrm{i}$ shows the SEM image of the electrode particle distribution with melted debris that affects the microhardness of the deposited workpiece.

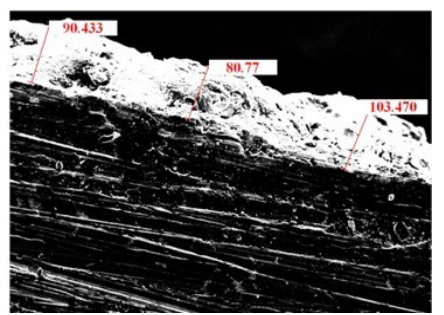

Fig. 2 Layer Thickness at low compaction load
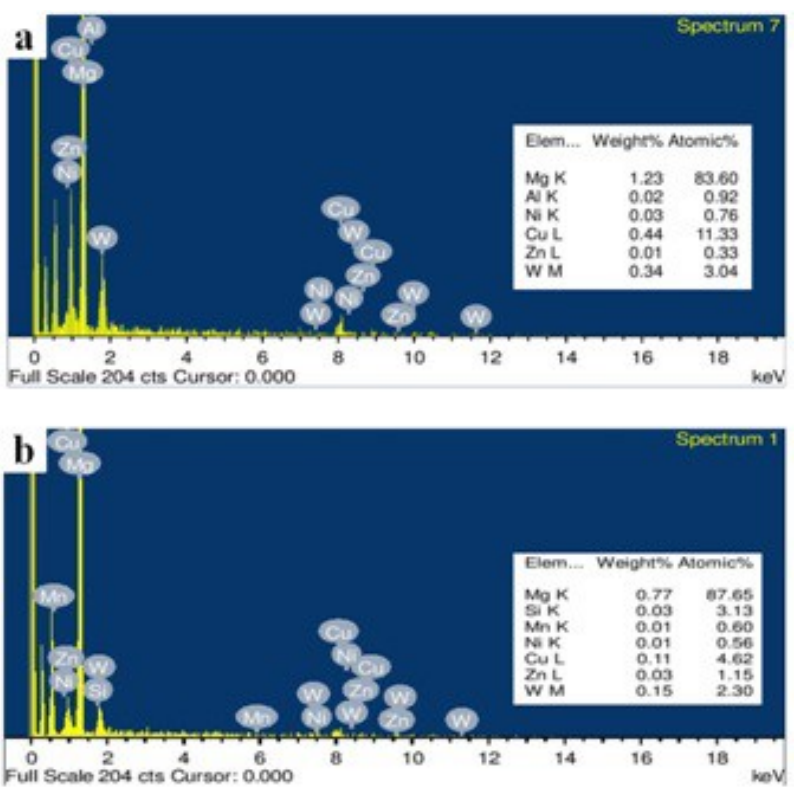

Fig. 3 EDS plot (a) low compaction load and (b) High compaction load
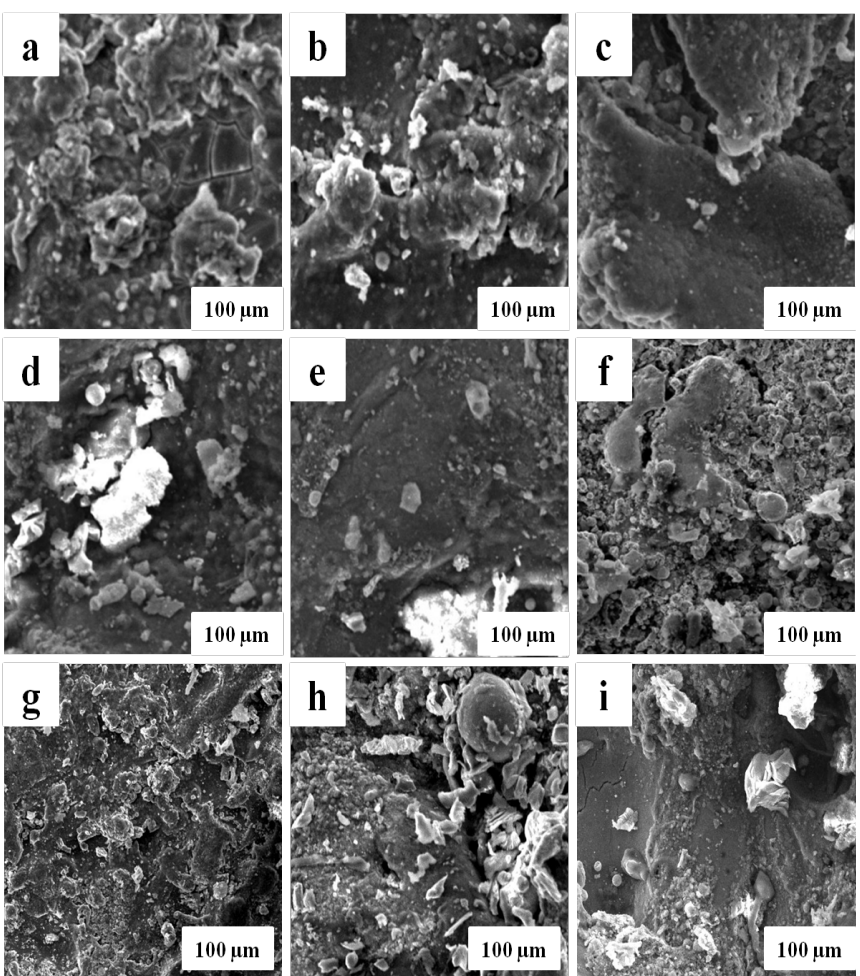

Fig. 4 SEM Microstructure of the deposited

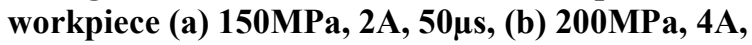

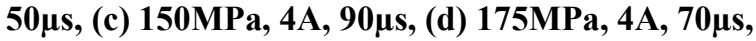
(e) $175 \mathrm{MPa}, 3 \mathrm{~A}, 90 \mu \mathrm{s}$, (f) $200 \mathrm{MPa}, 2 \mathrm{~A}, 90 \mu \mathrm{s}$, (g) 150

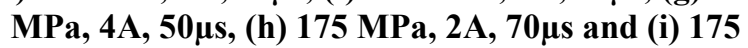
MPa, 4A, 90us 


\subsection{Effect of compaction load}

Compaction load is a critical factor during the electrode preparation. The electrode was prepared with the application of a higher load. The density of the compacted electrode is directly proportional to the amount of load applied. In this present investigation, the electrode was fabricated using WC-Cu powders through powder metallurgy method [12]. As increases the compaction load, the density of the electrode is high, results in lower MDR. The effect of compaction load on performance characteristics is illustrated in Fig. 5. As compaction load increases, the electrode performs like a denser solid object. Hence, the rate of deposition toward the workpiece surface is in minimum quantity. Thus, layer thickness and microhardness values decrease in the migrated surface. Fig.6a shows the SEM micrograph of workpiece deposited with low compaction load that created bulk deposition in the coating region. EDC with high compaction load developed the craters and cracked [13], that provides poorer surface finish as depicted in Fig.6b.
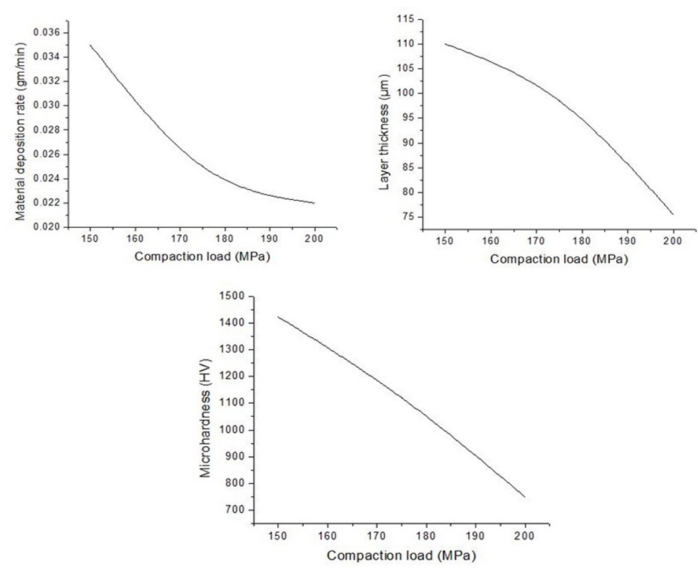

Fig. 5 Effect of compaction load on MDR, LT and MH

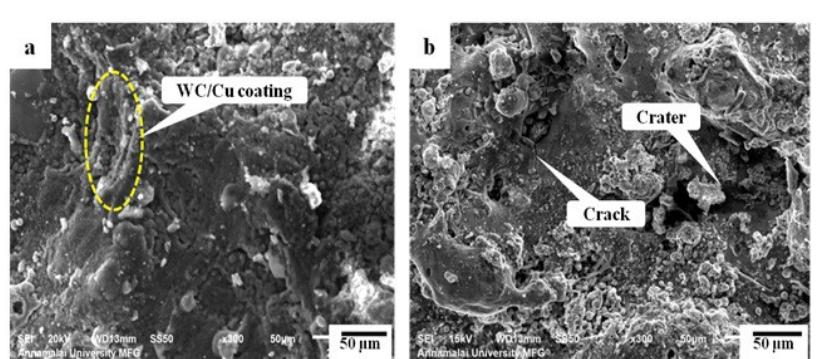

Fig. 6 SEM microstructure (a) Bulk and lump deposition at low compaction load (150 MPa) and (b) Formation of crater and crack at high compaction load (200MPa)

\subsection{Effect of current}

Current is the most significant parameter play vital role in migration process in EDM. During on time, current increases until it reaches a preset level, which is expressed as peak current. Generally, the peak current used for initiating electric spark between the electrode and workpiece and generating spark temperature for depositing the electrode material on workpiece surface [13]. The effect of current on performance characteristics (MMR, LT and MH) was presented in Fig.7. Fig 7a shows that the material deposition rate increases gradually with increases in current.
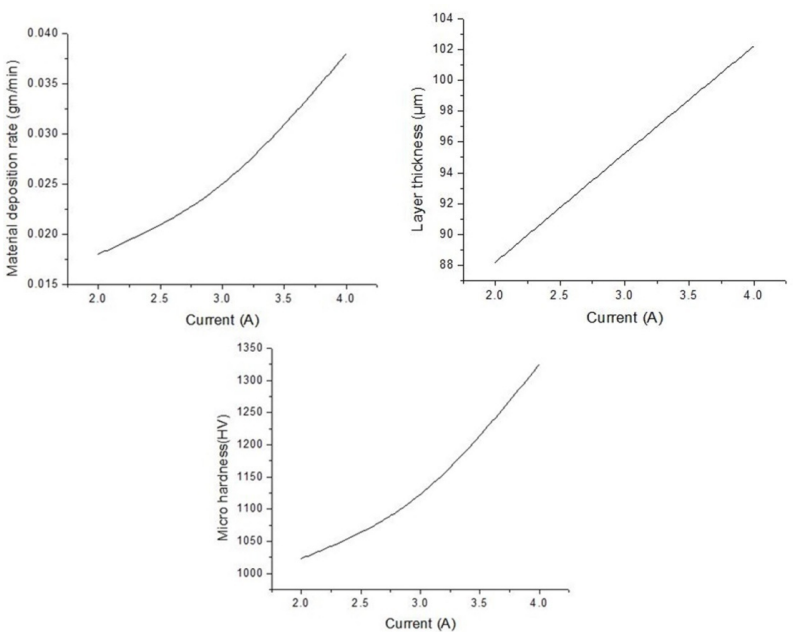

Fig. 7 Effect of current on MDR, LT and MH

With the increase in current, the erosion rate of the electrode is more, hence large quantity of materials is melted from the electrode and deposited on the workpiece; hence MMR and LT are high, which results in the bigger craters as depicted in Fig.8. The deposition of $\mathrm{W}-\mathrm{Cu}$ coating on work substrate increases with an increase in current. Hence, the microhardness of workpiece surface increased due to its higher deposition rate of electrode material and it is very much apparent from Fig. 7 and layer thickness of deposited surface increases with an increase in current. As the current increase, the amount of spark density increases; thus, the large amount of electrode material deposited on the workpiece surface [14]. 


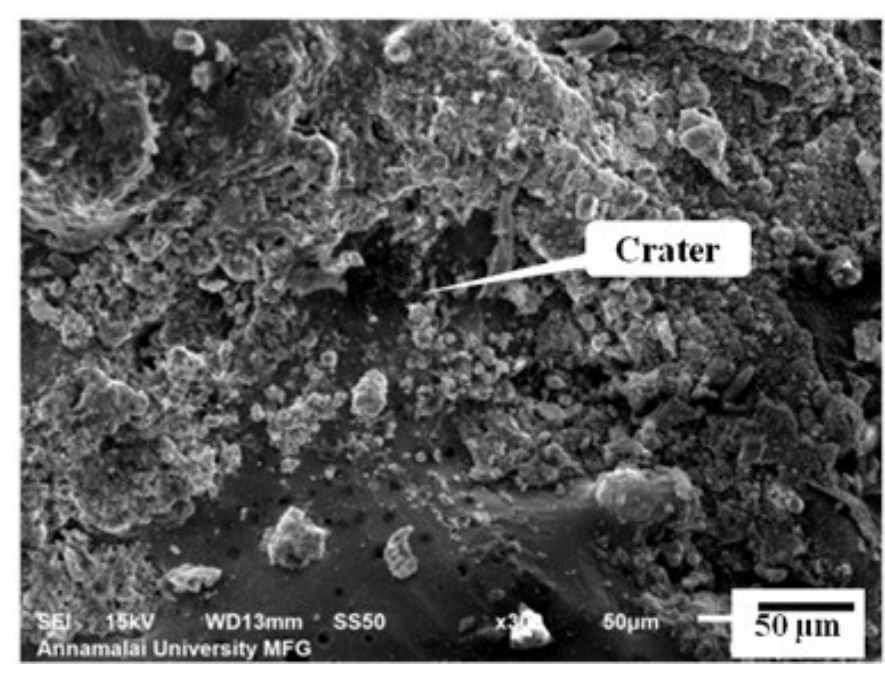

Fig. 8 The bigger crater at high current (4A)

\subsection{Effect of pulse on time}

In EDC process, pulse on time is considered as the main parameter, in which materials deposition rate highly occurs on the surface and MMR directly proportional to the quantity of discharge energy applied during on time which is controlled by the duration of pulses [15]. Effect of pulse on time on the response characteristics is shown in Fig. 9.

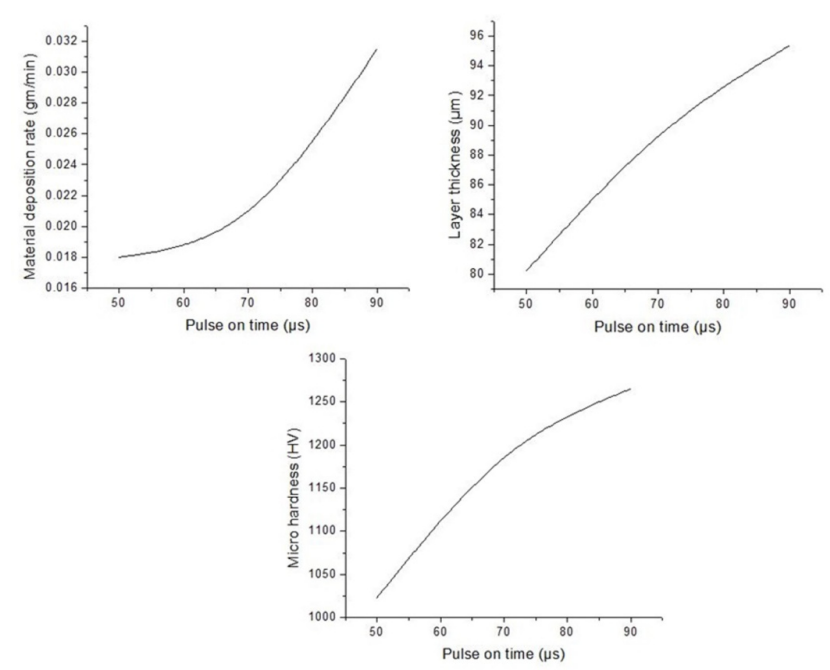

Fig. 9 Effect of pulse on time on MDR, LT and MH

With increases the pulse on time, the diameter of the plasma channel increases, thus the high quantity of material melted from the electrode and migrated on the surface of the workpiece. LT and MH increase with increases in pulse on time. It may be due to the high intensity of the spark, results in more deposition of the electrode with more craters [16]. In some cases, as increase the pulse on time, more globules formed in the deposited region [17] as depicted in Fig.10, that reduces the surface finish and microhardness.

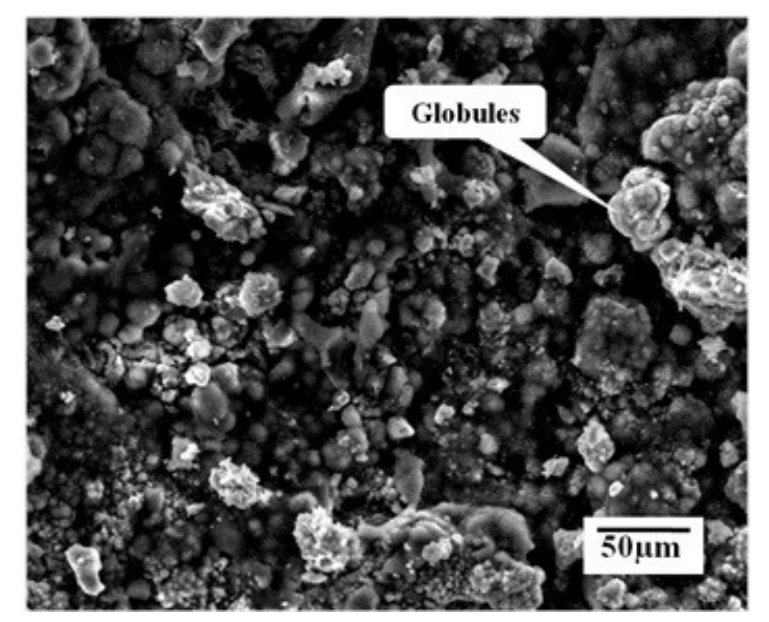

Fig.10 Formation of Globules at high pulse on time $(90 \mu \mathrm{s})$

\section{Conclusion}

The present paper studied the deposition of electrode materials on the magnesium alloy surface using WC-Cu powder metallurgy electrode by electrodischarge coating technique. From the results, the average microhardness of the migrated surface was 683 $\mathrm{HV}$, which eight times higher than the base material. The layer thickness of the migrated surface was 91.6 $\mu \mathrm{m}$. Micrographs of the deposited surface were analyzed by the SEM and EDS analysis. Based on the experimental results, it is evident that to achieve a higher MMR, layer thickness and microhardness, compaction load, was the most influential factor. Moreover, higher current settings yield a comparatively thick layer but provide a rough surface. Lower current provides a comparatively smooth surface with minimum layer thickness. EDC is a very practical technology having a good prospect in various industrial applications because the process is economical and does not need special equipment.

\section{Reference}

1. Bilal, A., Jahan, M.P., Talamona, D. and Perveen, A. (2019), Electro-discharge machining of ceramics: A review, Micromachines, 10(1):10

2. Kuriachen, B., Somashekhar, K.P. and Mathew, J. (2015), Multiresponse optimization of micro-wire electrical discharge machining process. The International Journal of Advanced Manufacturing Technology, 76(1-4):91-104. 


\section{Journal of Manufacturing Engineering, September 2020, Vol. 15, Issue. 3, pp 060-065}

3. Muralidharan, B., Chelladurai, H., Singh, P. and Roy, M.K. (2016), Single-spark analysis of electro-discharge deposition process. Materials and Manufacturing Processes, 31(14):1853-1864.

4. Elaiyarasan, U., Satheeshkumar, V. and Senthilkumar, C. (2018), Modeling of electrical discharge coating parameters using artificial neural network. Journal of Advanced Microscopy Research, 13 (1):79-84.

5. Liew, P.J., Yan, J. and Kuriyagawa, T. (2013), Experimental investigation on material migration phenomena in micro-EDM of reaction-bonded silicon carbide. Applied Surface Science, 276:731-743.

6. Ahmed, A. (2016), Deposition and analysis of composite coating on aluminum using Ti-B4C powder metallurgy tools in EDM. Materials and Manufacturing Processes, 31(4):467-474.

7. Mussada, E.K. and Patowari, P.K. (2015), Investigation of EDC parameters using $W$ and $C u$ powder metallurgical compact electrodes. International Journal of Machining and Machinability of Materials, 17(1):65-78.

8. Prakash, C., Singh, S., Pruncu, C.I., Mishra, V., Królczyk G., Pimenov, D.Y. and Pramanik, A. (2019), Surface modification of Ti-6Al-4V alloy by electrical discharge coating process using partially sintered Ti-Nb electrode. Materials, 12(7):1006.

9. Huang CH Yang A.B and Hsu, C.Y (2018), The optimization of micro EDM milling of Ti-6Al-4V using a grey Taguchi method and its improvement by electrode coating. The International Journal of Advanced Manufacturing Technology, 96 (9-12):3851-3859

10. Mohanty, S., Kumar, V., Das, A.K. and Dixit, A.R. (2019), Surface modification of Ti-alloy by micro-electrical discharge process using tungsten disulphide powder suspension. Journal of Manufacturing Processes, 37:28-41.
11. Tijo, D., Kumari, S. and Masanta, M. (2017), Hard and wear resistance TiC-composite coating on AISI 1020 steel using powder metallurgy tool by electro-discharge coating process. Journal of the Brazilian Society of Mechanical Sciences and Engineering, 39(11):4719-4734.

12. Siddique, A.R., Mohanty, S. and Das, A.K. (2019), Microelectrical discharge coating of Titanium alloy using WS2 and Brass P/M electrode, Materials and Manufacturing Processes, 34 (15): 1761-1774.

13. Phan, N.H. and Muthuramalingam, T. (2020), Multi Criteria Decision Making of Vibration Assisted EDM Process Parameters on Machining Silicon Steel Using Taguchi-DEAR Methodology. Silicon, https://doi.org/10.1007/s12633-020-00573-4

14. Rao, P.S., Purnima, N.S. and Prasad, D.S. (2018), Surface alloying of D2 steel using EDM with WC/Co P/M electrodes made of Nano and Micron sized particles. Materials Research Express, 6 (3)

15. Elaiyarasan, U., Satheeshkumar, V. and Senthilkumar, C. (2019), Microstructure study on electro discharge deposited magnesium alloy with semi sintered and sintered electrode. Materials Research Express, 6 (12).

16. Chakraborty, S., Kar, S., Dey, V. and Ghosh, S.K. (2018), The phenomenon of surface modification by electrodischarge coating process: a review. Surface Review and Letters, 25 (01):1830003.

17. Elaiyarasan, U., Satheeshkumar, V. and Senthilkumar, $C$. (2018), Experimental analysis of electrical discharge coating characteristics of magnesium alloy using response surface methodology. Materials Research Express, 5 (8): 086501 . 